\title{
Subcutaneous insulin B:9-23/IFA immunisation induces Tregs that control late-stage prediabetes in NOD mice through IL-10 and IFN $\gamma$
}

\author{
G. Fousteri • A. Dave • A. Bot • T. Juntti - S. Omid • \\ M. von Herrath
}

Received: 6 November 2009 / Accepted: 9 April 2010/Published online: 20 May 2010

(C) The Author(s) 2010. This article is published with open access at Springerlink.com

\begin{abstract}
Aims/hypothesis Subcutaneous immunisation with the 9-23 amino acid region of the insulin B chain (B:9-23) in incomplete Freund's adjuvant (IFA) can protect the majority of 4- to 6-week-old prediabetic NOD mice and is currently in clinical trials. Here we analysed the effect of B:9-23/IFA immunisation at later stages of the disease and the underlying mechanisms.

Methods NOD mice were immunised once s.c. with B:923/IFA at 5 or 9 weeks of age, or when blood glucose reached $10 \mathrm{mmol} / \mathrm{l}$ or higher. Diabetes incidence was followed in addition to variables such as regulatory $\mathrm{T}$ cell (Treg) induction, cytokine production (analysed by Elispot) and emergence of pathogenic $\mathrm{CD}^{+} / \mathrm{NRP}-\mathrm{V}^{+}$cells.

Results A single B:9-23/IFA immunisation protected the majority of NOD mice at advanced stages of insulitis, but not after blood glucose reached $13.9 \mathrm{mmol} / \mathrm{l}$. It increased Treg numbers and lost its protective effect after IFN $\gamma$ or IL10 neutralisation, but not in the absence of IL-4. $\mathrm{CD} 4^{+} \mathrm{CD} 25^{+}$and to a lesser extent IFN $\gamma$-producing cells from mice protected by B:9-23/IFA induced tolerance upon transfer into new NOD animals, indicating that a dominant Treg-mediated effect was operational. Reduced numbers of $\mathrm{CD}^{+} / \mathrm{NRP}-\mathrm{V}^{+}$memory $\mathrm{T}$ cells coincided with protection from the disease.
\end{abstract}

G. Fousteri $\cdot$ A. Dave $\cdot$ T. Juntti $\cdot$ S. Omid $\cdot$ M. von Herrath $(\bowtie)$ Diabetes Center, La Jolla Institute for Allergy and Immunology, 9420 Athena Circle, La Jolla, CA 92037, USA

e-mail: matthias@liai.org

A. Bot

Mannkind Corporation,

Valencia, CA, USA
Conclusions/interpretation Protection from diabetes after B:9-23/IFA immunisation cannot be achieved once diabetes is fully established, but can be achieved at most prediabetic stages of the disease. Protection is mediated by Tregs that require IFN $\gamma$ and IL-10. These findings should provide important guidance for ongoing human trials, especially for the development of suitable $\mathrm{T}$ cell biomarkers.

Keywords B:9-23 - IFN $\gamma \cdot$ IL-4 $\cdot$ IL-10 - Incomplete Freund's adjuvant $\cdot$ Tregs $\cdot$ Type 1 diabetes

$\begin{array}{ll}\text { Abbreviations } \\ \text { APC } & \text { Antigen-presenting cell } \\ \text { B:9-23 } & \begin{array}{l}\text { 9-23 Amino acid region of the insulin B } \\ \text { chain }\end{array} \\ \text { CTLA-4 } & \text { Cytotoxic T lymphocyte antigen } 4 \\ \text { FOXP3 } & \text { Forkhead box p3 } \\ \text { ICCS } & \text { Intracellular cytokine staining } \\ \text { IFA } & \begin{array}{l}\text { Incomplete Freund's adjuvant } \\ \text { IGRP }\end{array} \\ \text { Islet-specific glucose-6-phosphatase } \\ \text { PDLN } & \begin{array}{l}\text { catalytic subunit-related protein } \\ \text { Pancreatic draining lymph nodes }\end{array}\end{array}$

\section{Introduction}

Type 1 diabetes is one of the most common autoimmune diseases affecting the lives of millions of patients, among them children. As with most autoimmune diseases, many different autoantigens can be involved in the pathogenic response against the insulin-producing beta cells of the pancreas. In humans and mice, islet autoantibody specificities and epitopes for $\mathrm{CD}^{+}$and $\mathrm{CD}^{+} \mathrm{T}$ cells recognising insulin, GAD, islet tyrosine phosphatase IA-2 and islet- 
specific glucose-6-phosphatase catalytic subunit-related protein (IGRP) have been identified [1-4], but it is unclear which of these autoantigens are crucial for diabetes development. In NOD mice, the 9-23 amino acid region of the insulin B chain (B:9-23) is the dominant epitope involved in initiation of the disease [5-7]. In light of recent advances, various beta cell-specific therapeutic approaches have been developed and tested in animal models of diabetes, primarily in NOD mice [8]. Due to their specific immune-modulating effects, antigen-specific approaches represent preferable avenues for immune intervention [9].

Antigen-specific therapies can be applied before or after diabetes onset, depending on their efficacy [8-11]. The goal of beta cell antigen-specific approaches is to 're-educate' the immune system to stop it attacking the beta cells of the pancreas [9, 12, 13]. A large panel of autoantigenic epitopes has been established for humans and mice. Insulin-based interventions have shown very promising results in mice [14-17] and based on these findings, human clinical trials with insulin are currently on the way [18]. Prevention of diabetes following immunisation with insulin or insulin-derived epitopes has succeeded in many experimental settings, e.g. after intramuscular DNA vaccination, after oral treatment, or after intranasal and s.c. peptide vaccination in the presence or absence of enhancers such as incomplete Freund's adjuvant (IFA). For B:9-23 immunisation, most of these approaches have shown protection from diabetes, with the precise mechanism being unknown [1417, 19-22]. The great importance of better defining the underlying mechanisms is that this could provide a basis for defining biomarkers that would help monitor the effect of B:9-23 immunisation on the progression of beta cell autoimmunity in clinical trials.

With respect to s.c. B:9-23/IFA immunisation, all previously published studies were conducted at a rather early stage of the disease in the NOD mouse (4-6 weeks old) $[14,15]$. We reasoned that it would be important to carry out additional B:9-23/IFA immunisation studies at a later, more advanced stage of the disease ( 9 weeks old and recent-onset) in order to better reflect the human scenario, where prediabetic patients with different degrees of beta cell loss and targeted autoantigens are being recruited. Of great importance for current clinical trials currently implementing B:9-23/IFA immunisation after diabetes onset is our finding that this intervention may not be beneficial in patients with advanced stages of the disease, unless significant residual beta cell mass is present. Investigation of the underlying immunological mechanisms revealed enhancement of IFN $\gamma$, IL-10 and to lesser extent IL-4 production by Tregs in the spleen and the pancreatic draining lymph nodes (PDLN). Interestingly, IFN $\gamma$ and IL-10, but not IL-4 were required for the protective effect. Both populations, Tregs $\left(\mathrm{CD} 4^{+} \mathrm{CD} 25^{+}\right.$cells) and IFN $\gamma$-producing cells, pos- sessed long- or short-term regulatory properties respectively, demonstrating that a dominant regulatory effect was operational. In summary, we report here that B:9-23/IFA immunisation operates through Tregs that produce IFN $\gamma$ and IL10 , and is an effective immune intervention strategy with the ability to halt diabetes progression at advanced stages of insulitis, but not long after disease is established.

\section{Methods}

Mice NOD/LtJ and NOD/IL-4 $4^{-/-}$female mice were purchased from Jackson Laboratories (Bar Harbor, ME, USA). All mice were maintained at La Jolla Institute for Allergy and Immunology animal facility under pathogen-free conditions and handled in accordance with protocols approved by the organisation's Animal Care and Use Committee.

Blood glucose monitoring Blood glucose was monitored twice a week with a monitoring system (OneTouch Ultra; LifeScan, Milpitas, CA, USA). Diabetes was defined as two consecutive blood glucose values above $13.9 \mathrm{mmol} / \mathrm{l}$.

Definition of treatment groups Mice with blood glucose $<10 \mathrm{mmol} / \mathrm{l}$ at 4 or 9 weeks of age were characterised as prediabetic stages I and II respectively. Mice older than 10 weeks of age with blood glucose 10 to $13.9 \mathrm{mmol} / \mathrm{l}$ at first reading were defined as prediabetic stage III and those with blood glucose 13.9 to $19.4 \mathrm{mmol} / \mathrm{l}$ as recent-onset diabetes. Mice with blood glucose 19.4 to $33.3 \mathrm{mmol} / 1$ were characterised as established diabetes.

B:9-23 peptide treatments B:9-23 peptide (amino acid sequence: SHLVEALYLVCGERG) was purchased from Abgent (San Diego, CA, USA) with more than 95\% wt/wt purity. After dissolving in DMSO/DPBS, it was emulsified in IFA $(1: 1)$ at $0.5 \mathrm{mg} / \mathrm{ml}$. Injections of $200 \mu \mathrm{l}(100 \mu \mathrm{g})$ were performed s.c. at the neck area. This was done once in each mouse at either 5 or 9 weeks of age, or when blood glucose exceeded $10 \mathrm{mmol} / \mathrm{l}$. In control groups, mice were treated with DMSO/PBS/IFA or left untreated.

Flow cytometry After a $2.4 \mathrm{G} 2$ blocking step, cells were stained for CD4-PacificBlue CD $8 \alpha$-APCCy 7 (BDPharmingen, San Diego, CA, USA), and CD25-FITC and CD127-PeCy7 (eBioscience, San Diego, CA, USA). For intracellular forkhead box p3 (FOXP3) detection, cells were fixed with Fix/Perm buffer and stained with FOXP3-antigen-presenting cell (APC; eBioscience). For intracellular cytokine staining (ICCS), cells were initially surface-stained with CD4-PerCP5.5, CD25-APCCy7 and CD8a-PECy7, and then fixed and stained for IL-10-APC 
(BD-Pharmingen) and IFN $\gamma$-Pacific Blue (eBioscience) using a kit (Cytofix/Cytoperm; BD Biosciences) according to manufacturers' instructions. For NRP-V7 staining, cells were stained with 1:100 NRP-V7-PE tetramer [23] at room temperature for $30 \mathrm{~min}$. An antibody cocktail containing CD44-PacificBlue (Biolegend, San Diego, CA, USA), and CD4-PerCP5.5, CD19-FITC and CD8APC (BD-Pharmingen) was added and another incubation step followed. All antibody incubations were performed at $4{ }^{\circ} \mathrm{C}$ for $30 \mathrm{~min}$ (isotype controls were included). Cells were immediately acquired on a flow cytometer (LSRII; BD Biosciences) and analysed using a software package (FlowJo; Treestar, Ashland, OR, USA).

Assessment of cytokine production by single lymphoid cells All antibodies against IL-10, IL-4 and IFN $\gamma$ were from BD-Pharmingen except those for IL-17 (eBioscience). Briefly, 96-well millititer HA plates (Millipore, Bedford, MA, USA) were coated with capture antibodies at $5 \mu \mathrm{g} / \mathrm{ml}$. After a 10\% (vol./vol.) FCS/HL-1 blocking step, CD8depleted (clone 53-6.7; BD-Pharmingen) splenocyte suspensions were added at various dilutions ranging from $1 \times$ $10^{6}$ to $0.125 \times 10^{6}$ cells $/$ well and cultured in $2.5 \%$ (vol./vol.) FCS/HL-1 medium. Cells from blood or PDLN were plated at $0.25 \times 10^{6}$ cells/well. T cell-depleted splenocytes were added as APCs from age-matched non-treated NOD mice at a 1:1 ratio. B:9-23 peptide $(10 \mu \mathrm{g} / \mathrm{ml})$ was used in the presence of rhIL-2 $(50 \mathrm{U} / \mathrm{ml})$. After 2 days incubation at $37^{\circ} \mathrm{C}$ and extensive washes, detection antibodies were added at $4 \mu \mathrm{g} / \mathrm{ml}$ in PBS/Tween/1\% (vol./vol.) FCS. Following an avidin-peroxidase step (1:1,000 dilution; Vector Laboratories, Burlingame, CA, USA,) colour was developed with 3-amino9-ethylcarbazole (Sigma-Aldrich, St Louis, MO, USA) and $\mathrm{H}_{2} \mathrm{O}_{2}$. Finally, plates were rinsed in water, left to air-dry and spots representing cytokine-producing cells were counted using computer-assisted image analysis (Elispot reader; Carl Zeiss MicroImaging, Thornwood, NY, USA).

Immunohistochemistry Pancreases were immersed in Tissue-Tek OCT (Bayer, Torrance, CA, USA), quickfrozen and cut into $6 \mu \mathrm{m}$ tissue sections. After sections were fixed in $100 \%$ vol./vol. acetone and dried, they were re-hydrated in TBS and an avidin/biotin-blocking step was included (Vector Laboratories). To detect insulin and CD4 or $\mathrm{CD} 8$ in pancreatic sections, primary antibodies were applied as follows: guinea pig anti-swine insulin (1:300; Dako, Carpinteria, CA, USA), and anti-CD4 (RM4.5) or anti-CD8 $\alpha$ (Ly-2) immunohistochemistry (1:50; BDPharmingen). Primary and biotinylated secondary antibodies were added and colour reaction was obtained by sequential incubation with avidin-peroxidase and 3-amino9-ethylcarbazole, or alkaline phosphatase and Vector Blue AP III (SK-5300) (Vector Laboratories).
Immunofluorescent staining For evaluation of pancreatic cell division, sections were fixed for $15 \mathrm{~min}$ in $0.4 \%$ (wt/ vol.) paraformaldehyde. Concomitantly to anti-insulin, rat anti-Ki-67 (1:100; Dako) and hamster anti-CD3-PE (BDPharmingen) were used. Detection was achieved by highly cross-adsorbed goat anti-guinea pig Alexa-647 and highly cross-adsorbed goat anti-rat Alexa-488 (Invitrogen, Carlsbad, CA, USA). The hamster anti-PE primary antibody was added after incubation with these detection antibodies to entirely eliminate cross-detection. Sections were mounted with Prolong Antifade reagent (Invitrogen) and images were captured with a confocal microscope (SP5; Leica, Wetzlar, Germany) equipped with a $20 \times / 0.70$ numerical aperture immersion objective (Leica). Renormalisation and background subtraction was performed using ImageJ software (http://rsbweb.nih.gov/ij/).

Histological scoring Insulitis scoring was performed according to the following criteria: (1) severe insulitis or score of 4 to $5,50 \%$ or more of the islet area is infiltrated; (2) mild insulitis or score of 2 to $3,<50 \%$ of the islet area is infiltrated; (3) periinsulitis and no insulitis or score of 0 to 1 , infiltration is restricted to the periphery of islets or absence of cell infiltration.

In vitro stimulation and adoptive transfer experiments Lymphocytes from $>35$-week-old B:9-23/IFA-protected mice were pooled. Following a CD8-depletion step, cells were resuspended at $10 \times 10^{6} / \mathrm{ml}$ in $10 \%$ vol./vol. RPMI containing $50 \mathrm{U} / \mathrm{ml} \mathrm{rhIL-2}$ and $10 \mu \mathrm{g} / \mathrm{ml} \mathrm{B}: 9-23$, and cultured for 3 days. Next, $\mathrm{CD} 4^{+}$cells were purified and: (1) stimulated for ICCS; or (2) further purified into $\mathrm{CD} 4^{+} \mathrm{CD} 25^{+}$or $\mathrm{CD} 4^{+} \mathrm{CD} 25^{-}$, or into $\mathrm{IFN} \gamma^{+}$and $\mathrm{IFN} \gamma^{-}$ fractions. For ICCS, $\mathrm{CD} 4^{+}$cells were stimulated with platebound anti-CD3 $(5 \mu \mathrm{g} / \mathrm{ml})$ and soluble anti-CD28 $(2.5 \mu \mathrm{g} /$ $\mathrm{ml})$ for 4 to $16 \mathrm{~h}$ with brefeldin $\mathrm{A}(10 \mu \mathrm{g} / \mathrm{ml})$. $\mathrm{CD} 4^{+} \mathrm{CD} 25^{+}$ or $\mathrm{CD} 4^{+} \mathrm{CD} 25^{-}$cells were isolated with a kit $\left(\mathrm{CD} 4^{+} \mathrm{CD} 25^{+}\right.$ Regulatory $\mathrm{T}$ cell Isolation Kit; Miltenyi Biotech, Auburn, CA, USA). For purification of IFN $\gamma$-producing cells, the total $\mathrm{CD}^{+}$cell fraction was stimulated in vitro with platebound anti-CD3 $(4 \mu \mathrm{g} / \mathrm{ml})$ and soluble anti-CD28 $(2 \mu \mathrm{g} / \mathrm{ml})$ for $\sim 14 \mathrm{~h}$. IFN $\gamma^{+}$vs IFN $\gamma^{-}$cells were collected using a mouse IFN $\gamma$ secretion assay (Miltenyi Biotech) according to instructions. At least $1 \times 10^{6}$ total purified lymphocytes were adoptively transferred i.v. into 8- to 9-week-old NOD animals.

Antibody treatments Anti-IL-10 (clone JES5-2A5) and anti-IFN $\gamma$ (clone XMG1.2) were purchased from BDPharmingen. Mice (9 weeks old) were immunised with B:923/IFA and subsequently treated with $125 \mu \mathrm{g}$ antibody i.p. This was done twice at 11 and twice 12 weeks of age, totalling four times (plus control [rat anti-mouse IgG1 isotype]). Mice 
a

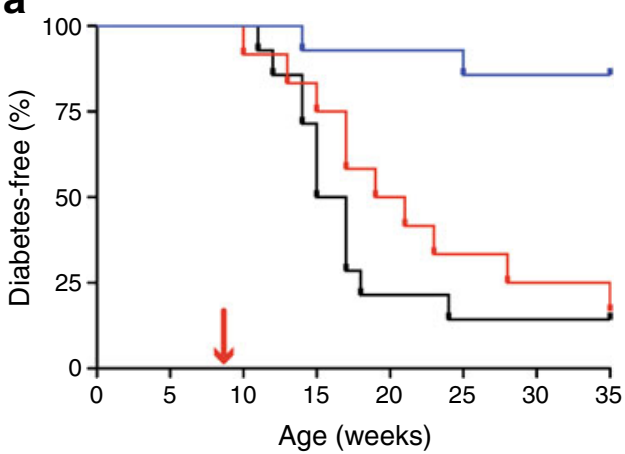

C

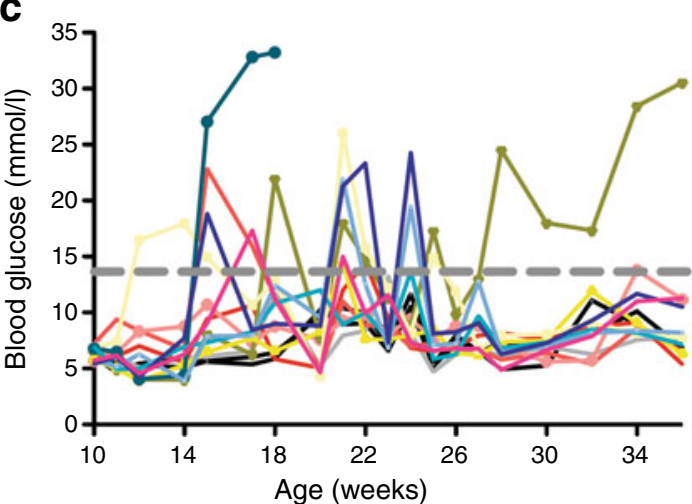

Fig. 1 Insulin B:9-23/IFA treatment given at all prediabetic stages protects from diabetes. a Percentage of NOD mice developing diabetes after a single $100 \mu \mathrm{g}$ B:9-23/IFA s.c. injection (blue line) at 9 weeks of age $(n=14)$ vs mice that were left untreated (black line, $n=$ 14 ) or were treated with PBS/IFA (red line, $n=12$ ). $p<0.001$. b As in a, but with immunisation at 5 weeks of age ( $n=12$ per group). All mice were monitored for blood glucose from 10 to $>35$ weeks of age. Each immunisation protocol was repeated in at least two independent experiments. $p<0.01$ compared with non-treated mice. Red arrows,

receiving $\mathrm{CD} 4{ }^{+} \mathrm{CD} 25^{+} \mathrm{T}$ cells anti-IFN $\gamma$ treatments started the next day (two times a week for 2 weeks).

Statistical analysis Data are expressed as a mean \pm SD. The statistical significance of the difference between b

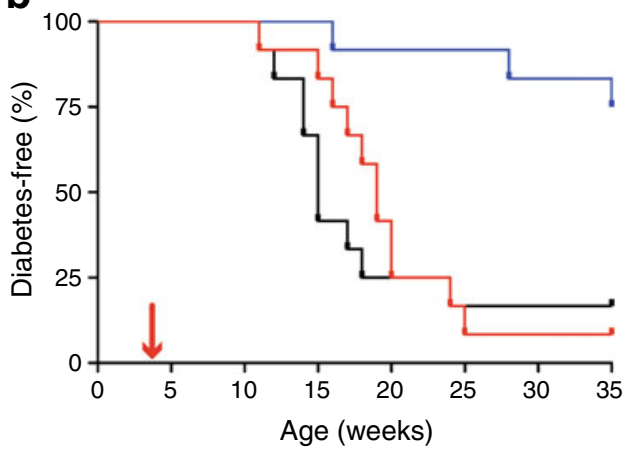

d

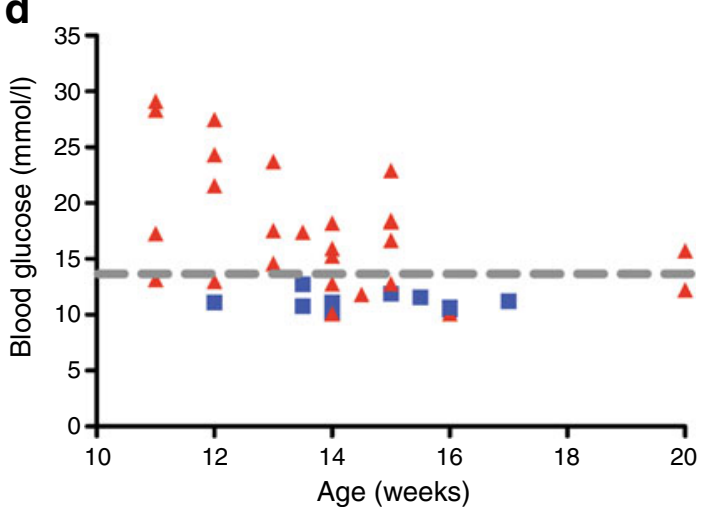

time of immunisation. c Individual blood glucose represented by differently coloured lines after B:9-23/IFA treatment at 9 weeks of age. One mouse that remained hyperglycaemic for more than three consecutive measurements was killed at 18 weeks of age. d Individual mice were treated with a single s.c. B:9-23/IFA injection when blood glucose was $>10 \mathrm{mmol} / \mathrm{l}$. Red triangles, individual entry blood glucose of mice progressing to diabetes; blue squares, entry blood glucose of mice that maintained normoglycaemia. Dashed line (c, d) indicates cut-off blood glucose value by which mice were considered diabetic

means was determined using the two-tailed Student's $t$ test or the logrank test. Statistical tests were conducted with PRISM software (Graphpad, San Diego, CA, USA), with significance defined as $* p<0.05, * * p<0.01$ and $* * * p<0.001$.

Table 1 B:9-23/IFA treatment s.c. protects normoglycaemic mice from diabetes development

\begin{tabular}{lllllllll}
\hline Treatment group & $\begin{array}{l}\text { Blood glucose } \\
(\mathrm{mmol} / \mathrm{l})\end{array}$ & $\begin{array}{l}\text { Mice } \\
\text { treated }(n)\end{array}$ & $\begin{array}{l}\text { Mice } \\
\text { protected }(n)\end{array}$ & $\begin{array}{l}\text { Mice } \\
\text { protected (\%) }\end{array}$ & $\begin{array}{l}\text { Diabetic } \\
\text { mice }(n)\end{array}$ & $\begin{array}{l}\text { Diabetic } \\
\text { mice }(\%)\end{array}$ & $\begin{array}{l}\text { Mice } \\
\text { fluctuating }^{\mathrm{a}}(n)\end{array}$ & $\begin{array}{l}\text { Mice fluctuating } \\
(\%)\end{array}$ \\
\hline${\text { Prediabetic stage I } \mathrm{I}^{\mathrm{b}}}^{\mathrm{a}}$ & $<6.6$ & 12 & 9 & 75 & 3 & 25 & 0 & 0 \\
Prediabetic stage II $^{\mathrm{c}}$ & $<6.6$ & 14 & 12 & 85.7 & 1 & 7.15 & 1 & 7.15 \\
Prediabetic stage III $^{\mathrm{d}}$ & $10-13.9$ & 19 & 10 & 52.63 & 7 & 36.842 & 2 & 10.53 \\
Recent-onset $^{\mathrm{e}}$ & $13.9-19.4$ & 11 & 0 & 0 & 8 & 72.728 & 3 & 27.273 \\
Established diabetes $^{\mathrm{e}}$ & $19.4-33.3$ & 7 & 0 & 0 & 7 & 100 & 0 & 0 \\
\hline
\end{tabular}

Values are ranges unless otherwise indicated

${ }^{\mathrm{a}}$ Blood glucose fluctuated for several weeks above and below $13.9 \mathrm{mmol} / \mathrm{l}$ before mice turned diabetic

${ }^{\mathrm{b}} 4$ weeks old; ${ }^{\mathrm{c}} 9$ weeks old; ${ }^{\mathrm{d}} 10$ weeks old; ${ }^{\mathrm{e}}$ older than 10 weeks 


\section{Results}

B:9-23/IFA immunisation s.c. can protect from advanced insulitis but not established diabetes Without intervention in the NOD mouse, islet destruction becomes evident by 4 weeks of age, with more islets becoming inflamed as the disease progresses. In our facility, diabetes manifests by 10 weeks of age, and as the disease progresses, greater numbers of insulin-producing beta cells are destroyed until more than 70 to $80 \%$ of the pancreatic islets are lost, which coincides with clinical manifestation of the disease. The anti-diabetogenic properties of B:9-23 peptide (100 $\mu$ g s.c.) a

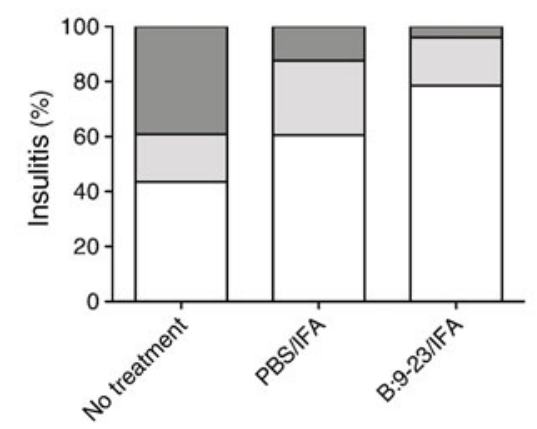

b

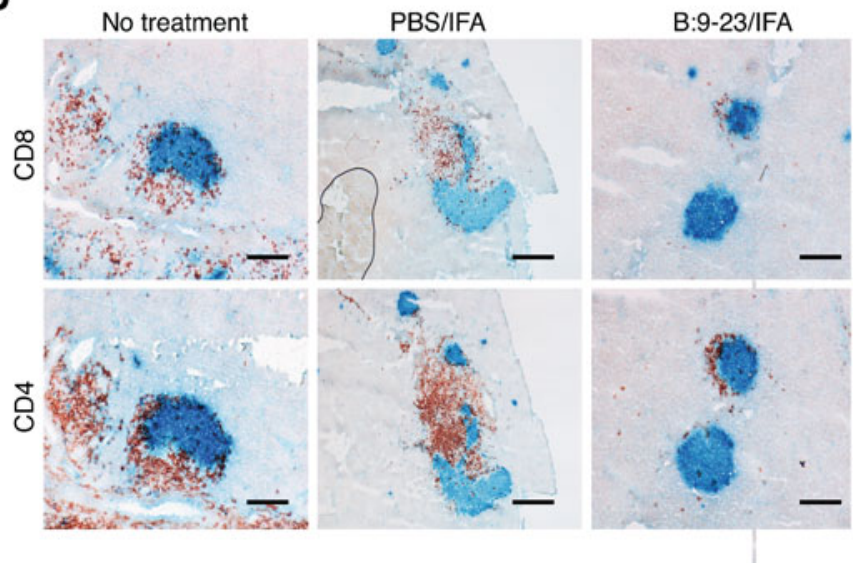

C
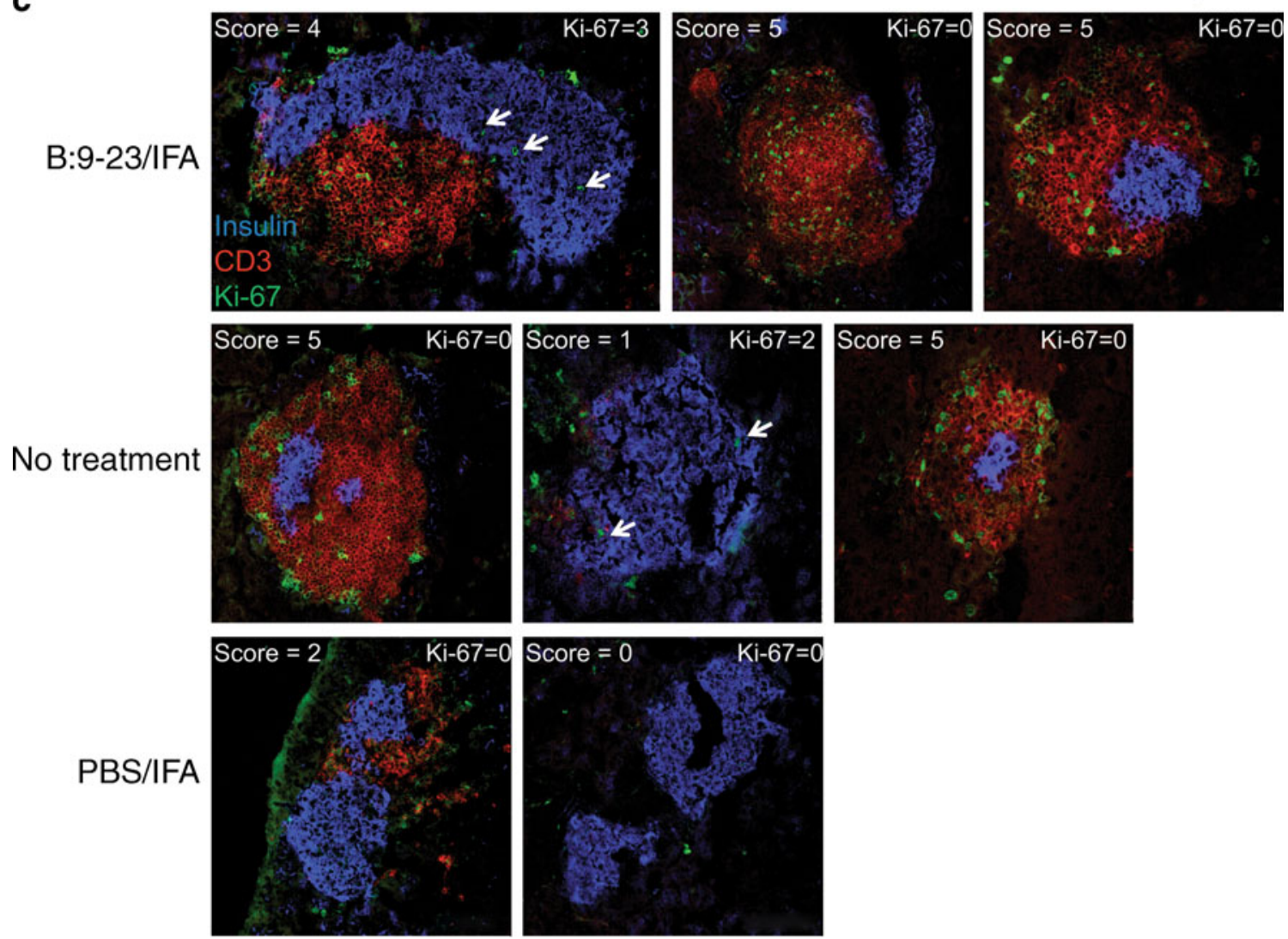

Fig. 2 Insulin B:9-23/IFA treatment decreases insulitis without enhancing beta cell proliferation. a Pancreatic sections from 12-week old normoglycaemic control and B:9-23/IFA-treated mice were stained for insulin/CD4 and scored for insulitis as described. Percentages represent the number of islets of a given score (white, score $0-1$; light grey, score 2-3; dark grey, score 4-5) over the total number of islets examined; at least six islets were examined per mouse (four mice per group). $p<0.01$ for B:9-23/IFA vs PBS/IFA. b Pancreatic histology.
Sections were co-stained for insulin (blue) and CD8 or CD4 as indicated (both red) and analysed at $10 \times$ magnification. c Pancreatic sections from the same mice as above (a, b) were stained for Ki-67 (green), insulin (blue) and CD3 (red) and analysed with confocal microscopy at $20 \times$ magnification. Representative Ki-67/insulin microphotographs showing the presence of Ki-67 cells within the pancreas with several degrees of insulitis (as shown) were analysed per group. White arrows, $\mathrm{Ki}-67^{+} / \mathrm{Ins}^{+}$double-stained cells 
emulsified in IFA were compared in vivo in NOD mice at prediabetic stages I and II, i.e. at 5 and 9 weeks of age, respectively (Fig. 1a, b, Table 1). B:9-23/IFA immunisation in 9-week old NOD mice was as effective as immunisation at 5 weeks of age. When blood glucose was monitored, mice immunised with B:9-23/IFA displayed significant fluctuations over a 25-week life span (Fig. 1c). Following 25 weeks of fluctuating blood glucose, most NOD mice treated remained stably normoglycaemic until $>35$ weeks of age, underlining the potential long-term benefit of this approach.

The above observations prompted us to test whether the same regimen could suppress ongoing diabetes. Blood glucose in NOD mice older than 10 weeks of age seems to reflect the degree of ongoing insulitis or alternatively the residual beta cell mass, i.e. mice with blood glucose $>13.9 \mathrm{mmol} / \mathrm{l}$ are considered to have more insulitis and less beta cell mass than mice with blood glucose $<13.9 \mathrm{mmol} / \mathrm{l}$. Therefore, as indicated in Table 1 , mice with blood glucose $>10 \mathrm{mmol} / \mathrm{l}$ were divided into three groups and treated with B:9-23/IFA. Our results show that this type of intervention is moderately effective in mice at prediabetic stage III and with blood glucose no greater than $13.9 \mathrm{mmol} / \mathrm{l}$. Mice from this group remained below $13.9 \mathrm{mmol} / \mathrm{l}$ during the total period of observation. When treated mice were plotted according to age, blood glucose at the time of treatment and progression to diabetes, an interesting trend emerged, namely that the earlier the disease manifestation and the higher the blood glucose, the more difficult it was to reverse hyperglycaemia (Fig. 1d).

Treatment with B:9-23/IFA s.c. reduces insulitis without enhancing beta cell proliferation To determine the extent of pancreatic tissue destruction following B:9-23/IFA immunisation, pancreases from 12-week-old non-diabetic mice immunised at 9 weeks of age were examined histologically. As indicated in Fig. 2a, b, the majority of islets in animals treated with B:9-23/IFA were minimally inflamed or had mild peri-insulitis. In contrast, most islets from mice that were treated or not with PBS/IFA had a much higher level of $\mathrm{CD}^{+}$and $\mathrm{CD}^{+}$cell infiltrates. Scoring of the islets showed that mice immunised with B:923/IFA had a much lower degree of insulitis than the control mice. Interestingly, PBS/IFA immunisation also resulted in some reduced inflammation compared with nontreated animals, suggesting that IFA alone is capable of affecting the diabetogenic process to some degree in the NOD mouse.

B:9-23 immunotherapy s.c. (1) preserved greater numbers of non-inflamed islets; (2) did not establish normal blood glucose during the first post-immunisation period in prediabetic NODs; and (3) restored normoglycaemia in some prediabetic stage III NOD mice. We therefore sought to address whether beta cell regeneration was involved. To test this, pancreatic sections were co-stained for insulin and Ki-67, and analysed histologically. Interestingly, as shown in Fig. 2c, few Ki-67/insulin double-positive beta cells could be detected, irrespective the treatment. Thus, we concluded that B:9-23/IFA immunisation did not affect beta cell replication, but instead modulated the autoreactive immune response, an observation that also explains why this regimen is not effective at more advanced stages of the disease, when greater beta cell mass is lost.

B:9-23/IFA therapy augments Tregs and results in loss of autoreactive CD8 cells We reasoned that an effect on Tregs and autoaggressive leucocytes would explain the protection from type 1 diabetes observed after B:9-23/IFA therapy. The frequency of Tregs determined as $\mathrm{CD} 4^{+} \mathrm{CD} 25^{+}$ $\mathrm{CD}_{12} 7^{\text {low }} \mathrm{FOXP}^{+}$was followed in blood, spleen and PDLN of mice immunised at 9 weeks of age. Approximately 2 to 3 weeks after immunisation, elevated Treg frequencies and numbers were found in all compartments, except for blood (Fig. 3a-c). These increases were also evident when the total cell numbers in spleen or PDLN were taken into account (Fig. 3d-e). Treg frequency at later

Fig. 3 Insulin B:9-23/IFA treatment induces Tregs that protect from diabetes. a Treg $\left(\mathrm{CD} 4^{+} \mathrm{CD} 25^{+} \mathrm{FOXP} 3^{+} \mathrm{CD} 127^{\text {low }}\right)$ frequency in the PDLN, (b) spleen and (c) blood of NOD mice immunised with B:923/IFA (white bars) or PBS/IFA (grey bars) s.c. at 9 weeks of age or left untreated (black bars). Treg frequency in the blood was monitored for 3 consecutive weeks after immunisation (as indicated), whereas in PDLN and spleen Treg frequency was monitored for 2 consecutive weeks as shown. The experiment was repeated at least twice with three to four mice per group (ND, not done). $p<0.05$ for PDLN at 12 weeks and $p<0.01$ for spleen at 11 weeks of age when B:9-23/IFA is compared with controls. d Total Treg numbers in PDLN and (e) the spleen. The Treg percentage for each individual mouse was multiplied with its respective total spleen or PDLN lymphocyte number. Trypan blue staining was used to exclude dead cells. $p<0.01$ for PDLN at 12 weeks, $p<0.05$ and $p<0.01$ for spleen at 12 and 11 weeks of age respectively (B:9-23/IFA vs controls). Mice analysed were those analysed above $(\mathbf{a}-\mathbf{c})$. f Representative flow cytometry plots as indicated in the PDLN and spleen at 12 weeks of age, indicating the $\mathrm{CD} 25^{+} \mathrm{FOXP}^{+}$cells after gating on $\mathrm{CD} 4^{+} \mathrm{CD} 8^{-} \mathrm{CD} 127^{\text {low }}$ lymphocytes. g, h CD8-depleted lymphocytes from B:9-23/IFA-treated and protected mice ( $>35$ weeks) were pooled and cultured for 3 days in the presence of B:9-23 $(10 \mu \mathrm{g} / \mathrm{ml})$ and $\mathrm{rhIL}-2(50 \mathrm{U} / \mathrm{ml})$. Subsequently, $\mathrm{CD} 4{ }^{+} \mathrm{CD} 25^{+}$(Tregs) or $\mathrm{CD} 4^{+} \mathrm{CD} 25^{-} \mathrm{T}$ cells were isolated and adoptively transferred to 8 - to 9-week-old new prediabetic NOD animals. The $\mathrm{CD} 4 / \mathrm{CD} 25$ profile of the cells prior to purification is shown above $(\mathbf{g})$. h Diabetes incidence in NOD animals after receiving $>1 \times 10^{6} \mathrm{CD}^{+} \mathrm{CD} 25^{+}$or $\mathrm{CD}^{+} \mathrm{CD} 25^{-} \mathrm{T}$ cells i.v. Donor cells were derived from mice treated at either 5 or 9 weeks of age; $\mathrm{CD} 25^{+} n=8, \mathrm{CD} 25^{-} n=14 ; p<0.05$. i Mean percentage and (j) total number of $\mathrm{NRP}-\mathrm{V}^{+} \mathrm{CD}^{+}$cells in the spleen after gating on live $\mathrm{CD} 4^{-} \mathrm{CD} 19^{-}$lymphocytes from 12 -week-old mice immunised at 9 weeks of age with B:9-23/IFA and control. $p<0.05$ 


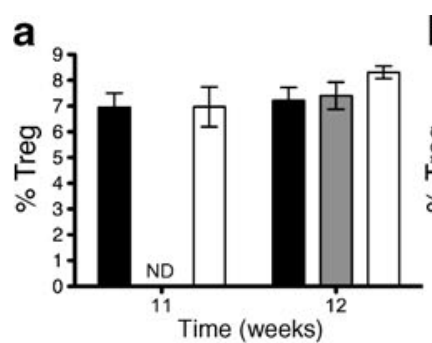

d
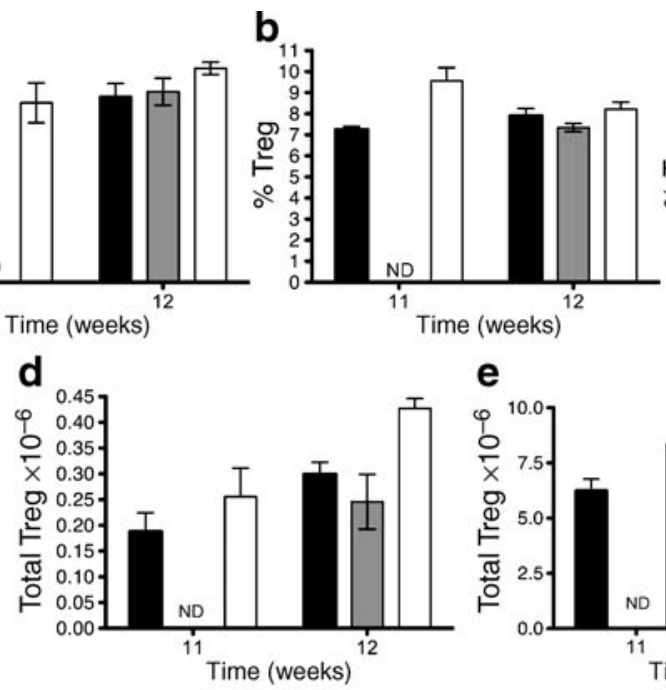

$C_{8}$

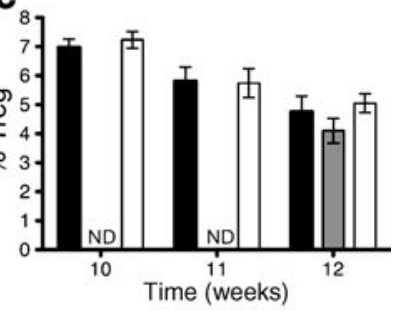

e

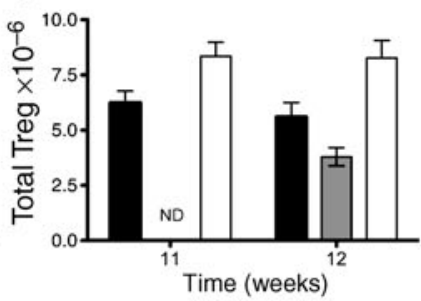

f
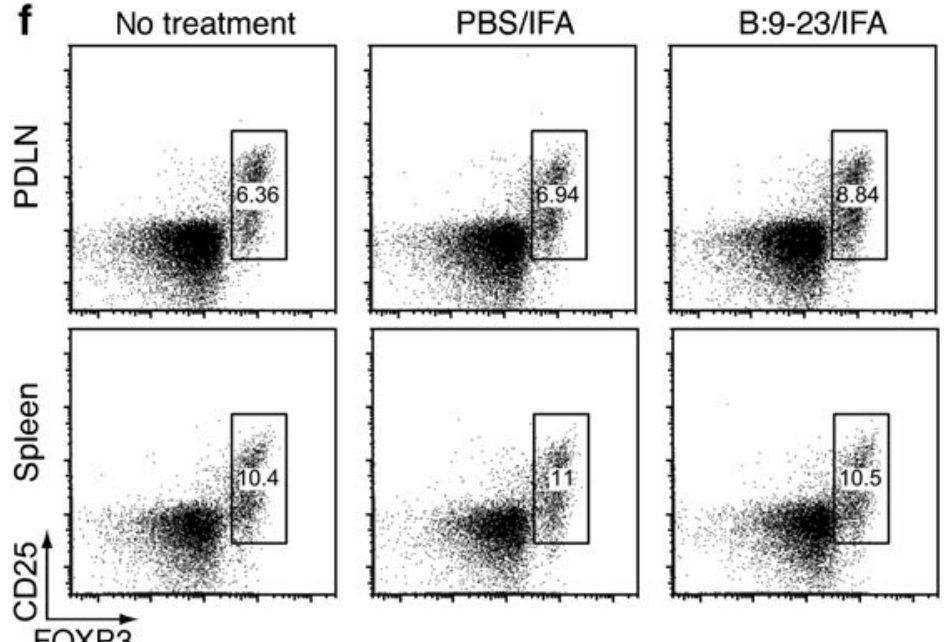

g
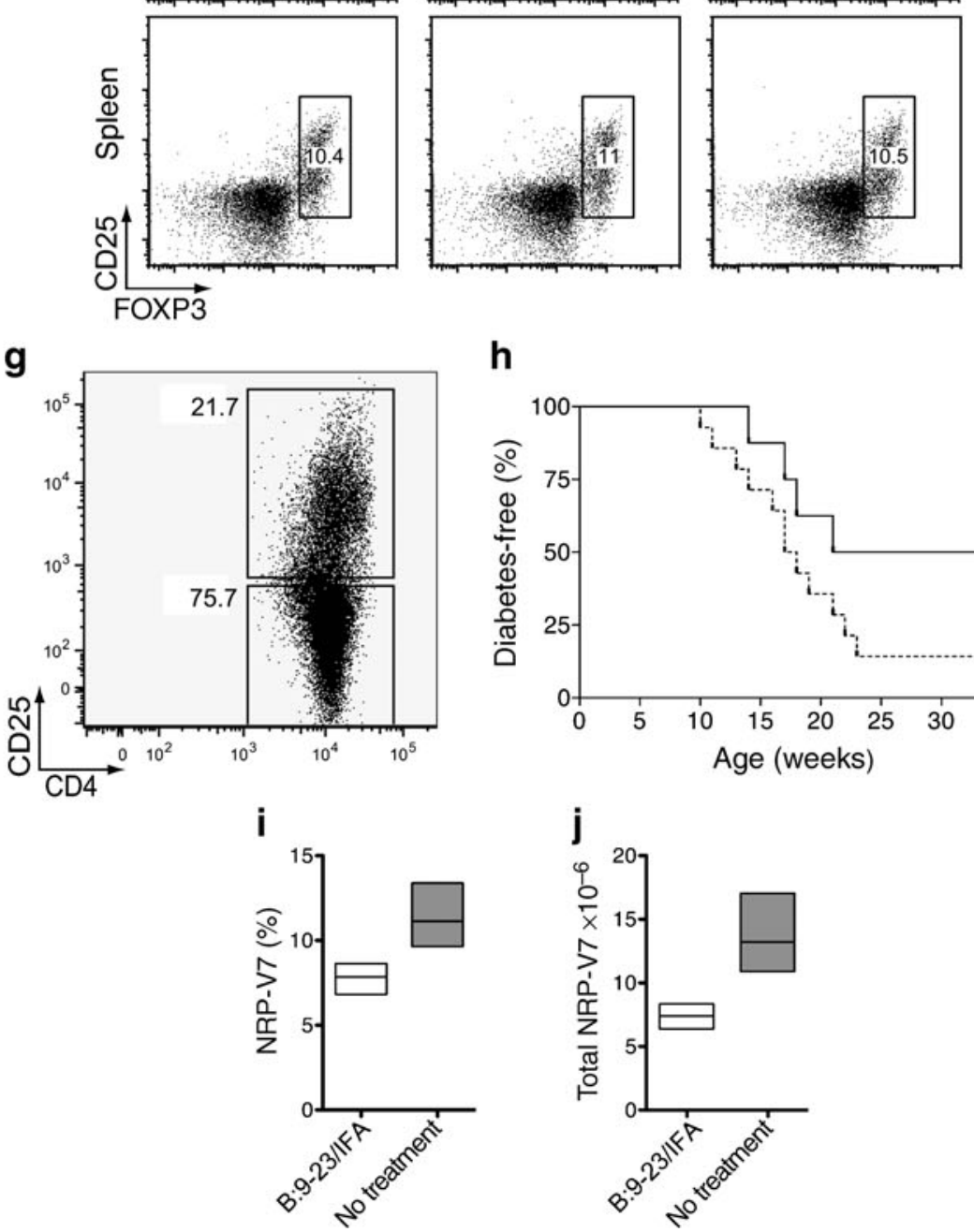

h
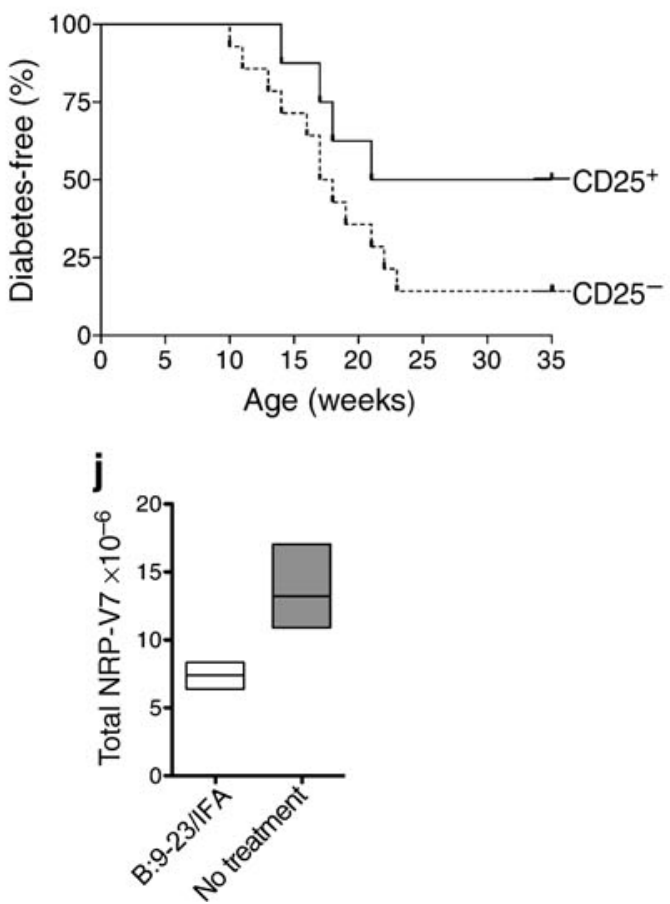
time points, i.e. 6 to 7 weeks post immunisation was not significantly higher than in control groups, although, in controls, a significant reduction in total lymphocyte numbers was seen, perhaps due to diabetes-associated lymphopenia (data not shown). In adoptive transfer experiments, in which $\mathrm{CD} 4{ }^{+} \mathrm{CD} 25^{+} \mathrm{T}$ cells from protected mice were transferred i.v. into 8- to 9-week-old prediabetic NOD mice, protection from diabetes was observed (Fig. 3g-h). Culturing the cells with B:9-23 increased the total fraction of $\mathrm{CD} 4{ }^{+} \mathrm{CD} 25^{+}$cells and enhanced their suppressive activity, perhaps due to further enrichment with B:9-23specific cells (expansion greater than two- to threefold, cells $>50 \% \mathrm{FOXP}^{+} \mathrm{CD} 127^{\text {low }}$, data not shown).
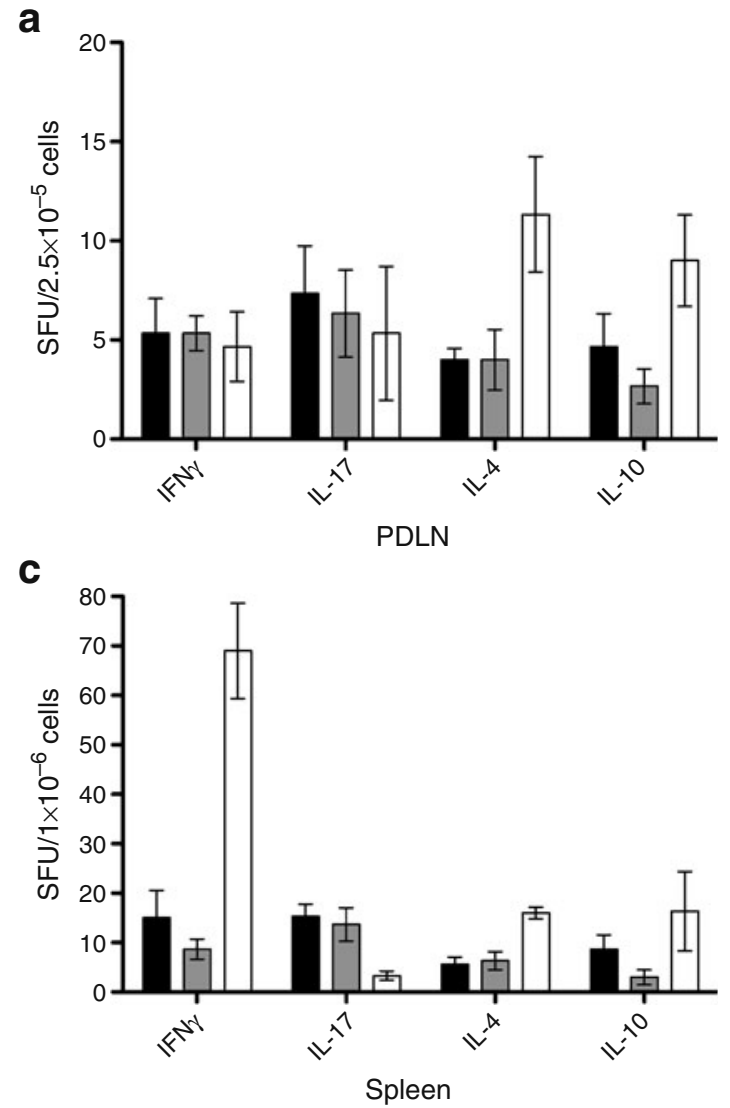

Fig. 4 Insulin B:9-23/IFA treatment induces IFN $\gamma /$ IL-4 production in the spleen and IL-10/IL-4 in the PDLN. In B:9-23/IFA immunised mice (white bars), laboratory measurements showed an increase in IL$10(p<0.05)$ and IL-4 $(p<0.05)$ cytokine-producing cell numbers in the PDLN (a), in IFN $\gamma$ in the blood $(p<0.05)(\mathbf{b})$, and in IFN $\gamma$ and IL4 in the spleen $(p<0.01$ and $p<0.05$, respectively) (c) vs no treatment (black bars) and PBS/IFA treatment (grey bars). In the spleen (d), the IFN $\gamma:$ IL-17 ratio was increased more than tenfold $(p<0.01)$ The number of B:9-23-reactive $\mathrm{CD}^{+}{ }^{\mathrm{T}}$ cells producing IFN $\gamma$, IL-17, IL-4 and IL-10 in all secondary lymphoid organs analysed was calculated by deducting the number of spot-forming units (SFU) without stimulation from the number of SFU after B:9-23 re-stimulation. In each condition, $50 \mathrm{U} / \mathrm{ml}$ of rhIL-2 was added to the culture, which
Since insulin is the initiating autoantigen in the NOD mouse, but other autoantigens such as GAD65 are recognised as the disease progresses [24], protection after B:9-23/IFA immunisation in older NOD mice was probably also mediated by bystander suppression mechanisms [25-28]. To test this premise, cells from spleens of mice immunised with B:9-23/IFA were stained with the MHC class I tetramer NRP-V7, which identifies diabetogenic $\mathrm{CD}^{+} \mathrm{T}$ cells [23]. As shown in Fig. 3i-j, a great reduction in $\mathrm{NRP}-\mathrm{V} 7^{+} \mathrm{CD} 8^{+} \mathrm{CD} 19^{-}$cells was seen in spleen, indicating that prevention of type 1 diabetes through B:9-23/IFA immunisation resulted in loss of NRPV-7 T cells. b
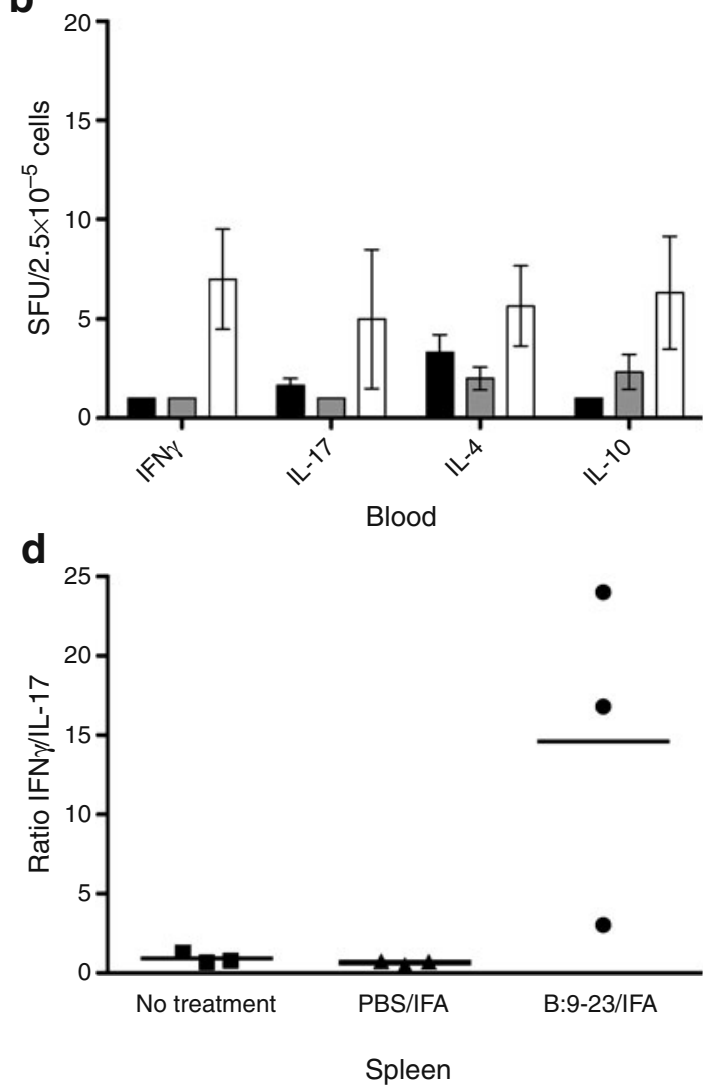

lasted for 3 days. In the spleen, Elispot using CD8-depleted lymphocytes was performed, whereas in the blood and PDLN, T cell-depleted splenocytes from age-matched non-treated NOD mice were added as APCs. The numbers of SFU without stimulation (background), which were subtracted to generate the experimental results for IFN $\gamma$, IL-17, IL-4 and IL-10, were: for spleen $80 \pm 20$, $150 \pm 45,115 \pm 30$ and $25 \pm 15$; for PDLN $43 \pm 13,75 \pm 25,48 \pm 12$ and $45 \pm 15$; and for blood: $35 \pm 12,75 \pm 15,60 \pm 25$ and $6 \pm 5$, respectively. The analysis shown is from 12-week-old immunised or non-treated NOD animals; similar results were obtained from two independent experiments with three mice per group. One representative experiment is shown 
B:9-23 immunisation increases protective B:9-23-specific $I F N \gamma$ and IL-10 cytokine production In diabetes, a beneficial outcome of immunisation has been frequently associated with changes in the endogenous cytokine microenvironment. A shift from pathogenic to protective (IL-4, IL-10) cytokine production has been described [29, 30]. Mice immunised with B:9-23/IFA were assessed by Elispot analysis for the production of four cytokines: IL-10, IL-4, IFN $\gamma$ and IL-17. As shown in Fig. 4, upon in vitro restimulation with the B:9-23 peptide, an increase of IFN $\gamma$ cytokine-producing cells in the spleen and of IL-10 in the PDLN was seen. Elevation of IL-4 production in both lymphoid compartments was also observed. In addition, when the number of IFN $\gamma$-producing cells for individual mice was divided by the number of Th17 cells and averaged per experimental group, a strong increase in the IFN $\gamma:$ IL-17 ratio in the spleen of mice immunised with B:9-23/IFA was seen (Fig. 4d).

Based on our Elispot results, IL-4, IFN $\gamma$ and IL-10 were good candidates for mediating the protection offered by B:9-23/IFA immunisation. To test this in vivo, mice receiving B:9-23/IFA injections were treated twice i.p. with anti-IL-10 or anti-IFN $\gamma$ neutralising antibodies. Interestingly, neutralisation of either cytokine following B:9-23/IFA treatment restored normal progression towards diabetes in the NOD mouse (Fig. 5a). In contrast, IL-4 was not required for protection, since B:923/IFA immunisation was as effective in IL-4-deficient NOD as in wild-type mice (Fig. 5b). NOD mice in which anti-IL-10 or anti-IFN $\gamma$ neutralisation was performed at the same age showed similar kinetics of diabetes development (data not shown). Thus, B:9-23/IFA protection induces IL-10 and IFN $\gamma$, which are required for establishing tolerance.

\section{B:9-23/IFA-induced IFN $\gamma$ supports the suppressive activity} of $\mathrm{CD}^{+} \mathrm{CD} 25^{+}$cells and shows immunomodulatory action The potential role of IFN $\gamma$ during tolerance reestablishment in diabetes is not well known. Interestingly, as shown in Fig. 6a, upon in vitro re-stimulation with platebound anti-CD3 and soluble anti-CD28, CD $4^{+} \mathrm{CD} 25^{+}$and $\mathrm{CD} 4{ }^{+} \mathrm{CD} 25^{-}$populations were both able to produce IFN $\gamma$ and IL-10, with $\mathrm{CD} 4{ }^{+} \mathrm{CD} 25^{+}$Tregs producing ten times more. Intracellular co-staining for FOXP3 showed significant IFN $\gamma$ production by this population, although FOXP3 levels were reduced within the $\mathrm{CD} 4{ }^{+} \mathrm{CD} 25^{+}$ population after anti-CD3/CD28 stimulation (Fig. 6a). When IFN $\gamma$ production was blocked after $\mathrm{CD} 4^{+} \mathrm{CD} 25^{+}$ (Treg) transfer, the protective effect was abolished (Fig. 6b). These results show that B:9-23/IFA immunisation induces Tregs that can modulate the function or differentiation of diabetogenic effector $\mathrm{T}$ cells through IFN $\gamma$ production.
To further elucidate the immunoregulatory properties of IFN $\gamma, \mathrm{CD}^{+} \mathrm{IFN}^{+}$cells were adoptively transferred into new 8- to 9-week-old prediabetic hosts. It was found that this population of cells was able to delay, but not protect NOD recipients from diabetes development (Fig. 6c, d). On the other hand, IFN $\gamma^{-}$cells failed to convey any protection, causing instead some acceleration of the disease. The fact that $\mathrm{CD}^{+} \mathrm{IFN}^{+}$cell transfer led to only transient protection from diabetes development could imply that (1) the number of cells transferred was limited (less than $1 \times 10^{6}$ cells/recipient), (2) pathogenic cells were also enriched, (3) too few regulatory cells were enriched or (4) the regulatory properties of those cells were lost with time.
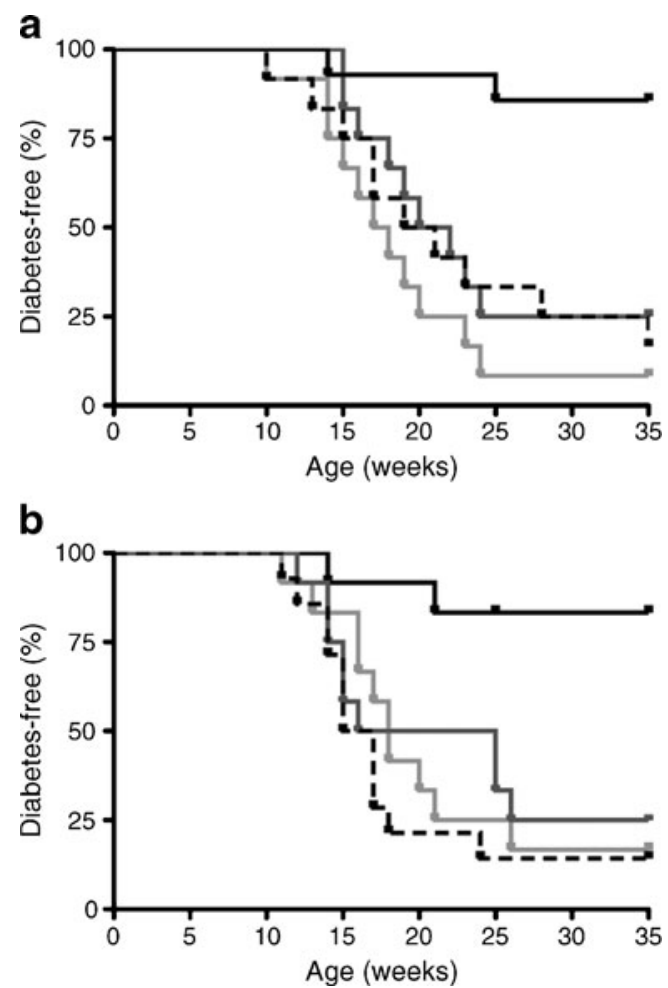

Fig. 5 The protective effect of B:9-23/IFA is mediated by IFN $\gamma$ and IL-10, but not by IL-4 production. a Percentage of mice developing diabetes upon in vivo neutralisation of IFN $\gamma$ (light grey line) or IL-10 (dark grey line) after s.c. treatment with insulin B:9-23/IFA of 9-week old NODs. Control, B:9-23/IFA treated with the isotype anti-rat IgG (black line) or PBS/IFA alone (dashed black line) are also depicted. Mice were treated for both neutralising antibodies with two intraperitoneal injections per week, at 10 and 11 weeks of age. Anti-IFN $\gamma$ (clone XMG1.2), anti-IL-10 (clone JES5-2A5) or isotype control were given to mice $(150 \mu \mathrm{g}$ per animal per injection) i.p. The mice received a total of four antibody injections. b Diabetes progresses normally in $\mathrm{Il}-4^{-/}$NOD mice (light grey line), similarly to $\mathrm{Il}-4^{-/}$NOD mice treated with PBS/IFA (dashed black line) and IL4 wild type (WT) controls (black line). Upon B:9-23/IFA immunisation tolerance is achieved irrespective of endogenous IL-4 levels (black line). At least 12 mice were included in each experimental group. $p<0.01$ compared with WT 
Fig. $6 \mathrm{CD} 4^{+} \mathrm{CD} 25^{+}$insulin B:9-23/IFA-induced cells (Tregs) mediate protection against diabetes through IFN $\gamma$ production. a Lymphocytes from protected B:9-23/IFA immunised mice were pooled and cultured for 3 days in the presence of B:9-23 $(10 \mu \mathrm{g} / \mathrm{ml})$ and rhIL-2 (50 U/ml). Subsequently, cells were stimulated for $4 \mathrm{~h}$ with plate-bound aCD3 $(5 \mu \mathrm{g} / \mathrm{ml})$ and soluble aCD28 $(2.5 \mu \mathrm{g} / \mathrm{ml})$, and assayed for cytokine production. The IL-10/ IFN $\gamma$ as well as the FOXP3/

IFN $\gamma$ profile after gating on the $\mathrm{CD} 4^{+} \mathrm{CD} 25^{+}$and $\mathrm{CD} 4^{+} \mathrm{CD} 25^{-}$ populations is shown. The isotype control for both cytokines is also shown for the $\mathrm{CD} 4{ }^{+} \mathrm{CD} 25^{+}$population. b Upon adoptive transfer of $\mathrm{CD} 4^{+} \mathrm{CD} 25^{+}$cells from protected mice, some $(n=6)$ received two anti-IFN $\gamma$ (clone XMG1.2) neutralising antibody injections $(150 \mu \mathrm{g} / \mathrm{each})$, one at 10 and the other at 11 weeks of age. At the time of adoptive transfer, recipients were 8 to 9 weeks old. Total i.p. injections per recipient, $n=4$. c Cells from above procedure (a) were sorted into $\mathrm{CD}^{+} \mathrm{IFN} \gamma^{+}$(black line) or $\mathrm{CD} 4^{+} \mathrm{IFN} \gamma^{-}$(grey line) populations as described above. d Approximately $1 \times 10^{6}$ of cells were adoptively transferred to 8- to 9-week-old prediabetic NOD mice and diabetes incidence was followed; $n=14$ for IFN $\gamma^{+}$cells (grey line), $n=12$ for no treatment (black line) and $n=10$ for IFN $\gamma^{-}$cells (black dashed line)
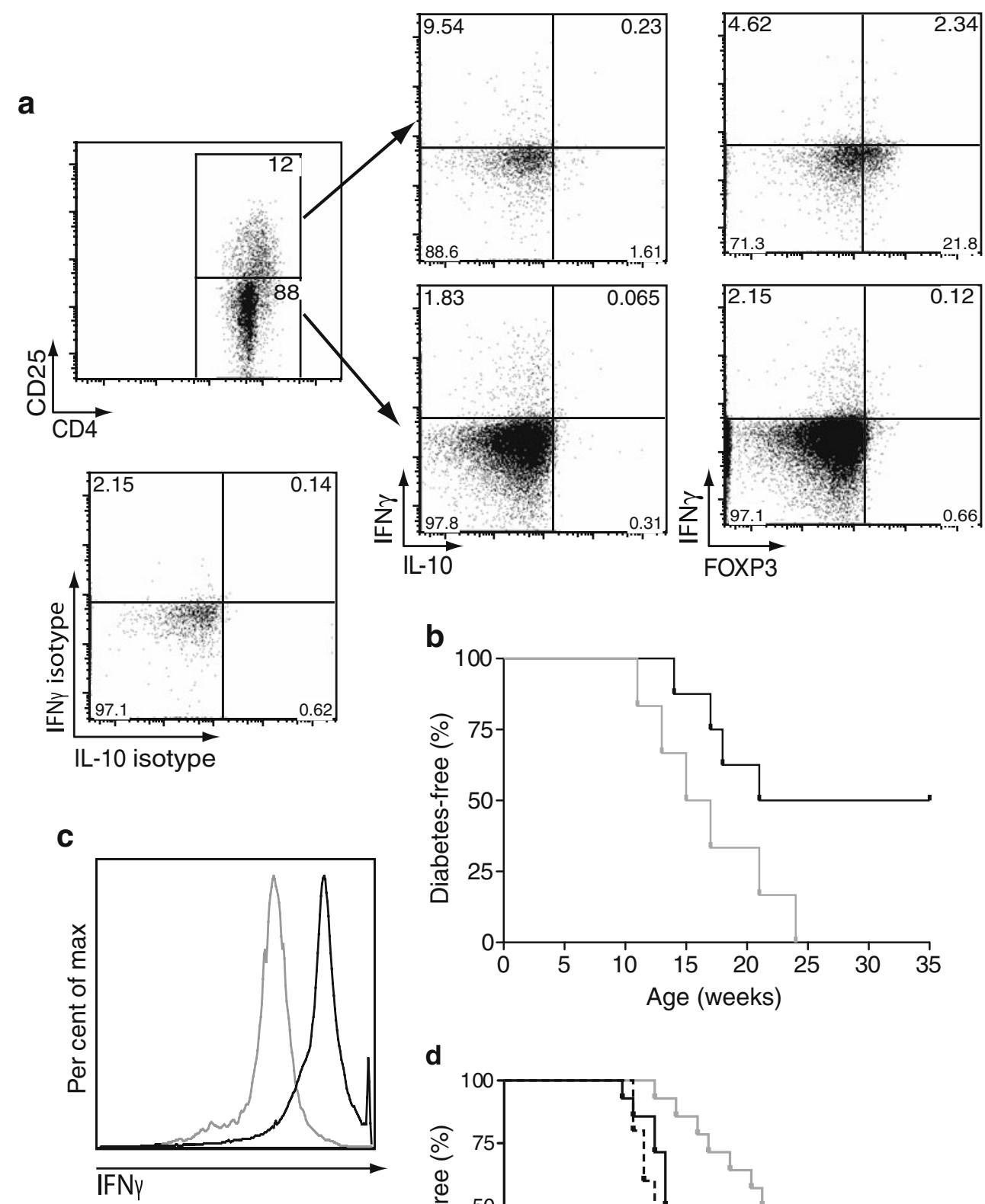

88.6

1.61
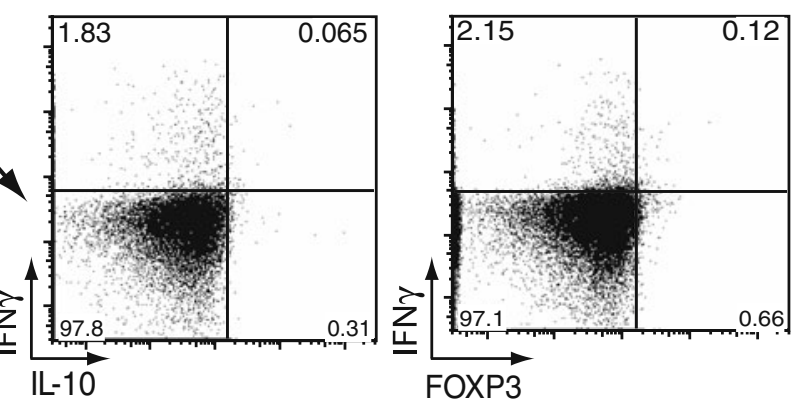

b

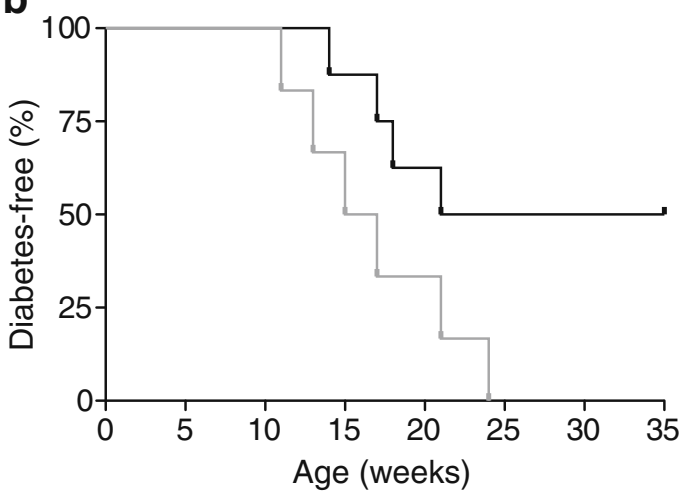

d

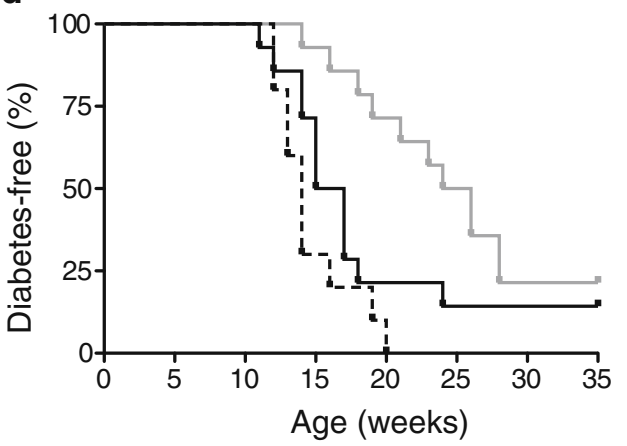

\section{Discussion}

Subcutaneous B:9-23/IFA treatment can effectively prevent diabetes when given at an early stage during disease development in NOD mice [14, 15]. Translation of this intervention to humans is in progress in early clinical trials [31], but it is not well known how the precise disease stage would affect therapeutic efficiency. In our study, B:9-23/ IFA immunisation given at more advanced prediabetic stages significantly protected NOD mice from diabetes development, albeit to a less pronounced degree in mice with higher (non-physiological) blood glucose values (10 $13.9 \mathrm{mmol} / \mathrm{l})$. However, this intervention was not efficacious in mice that had established signs of diabetes and greater loss of beta cell mass, probably because B:9-23/IFA was not able to increase beta cell regeneration. Histological examination of mouse pancreases showed reduced lymphocytic infiltration, which was not associated with islet proliferation, suggesting that this intervention predominantly affected the autoaggressive effector response. This was due to 
the induction of Tregs that required IL-10 and IFN $\gamma$, but not IL-4 to be operational in vivo. Our findings are of particular interest for the ongoing B:9-23/IFA human trial, since induction of such Tregs could hopefully be tracked in human blood and serve as a correlate of successful immunisation and, in the future, maybe even as a secondary trial outcome.

It is likely that B:9-23/IFA immunisation mainly affected endogenous beta cell-specific, regulatory (protective) immune responses. This involved shifts in cytokine production and was associated with reduction of auto-reactive $\mathrm{T}$ cells of other specificities, such as IGRP-specific CD8 lymphocytes. The immune response against IGRP in NOD mice was also reduced in another study in which tolerance was achieved with intranasal proinsulin [32]. Tregs in general play key roles in controlling many autoimmune processes. They can be identified by high levels of FOXP3 and IL-2R $\alpha$ (CD25) and/or production of certain immunoregulatory cytokines $[33,34]$. Their suppressive activity can be mediated by cell-to-cell contact or through cytokine production, with cytotoxic $\mathrm{T}$ lymphocyte antigen 4 (CTLA4), IL-10 and TGF-beta-1 being the most important mediators of their function in vivo [35-38]. In our study, augmented Tregs were found 2 to 3 weeks after immunisation (Fig. 3a-c). Whether these Tregs represent a de novo generated population from naive precursors or an expansion of the endogenous population is not known.

An increase in antigen-specific IFN $\gamma$, IL-4 and IL-10 production coincided with the time of Treg induction, since enhancement of B:9-23-specific IFN $\gamma$, IL-4 and IL-10 cytokine producing cells was seen 3 weeks after immunisation (Fig. 4). Neutralisation of IL-10 and IFN $\gamma$ reversed protection, resulting in hyperglycaemia. Blocking IFN $\gamma$ could also have diminished the action of autoaggressive lymphocytes, but in that case protection from disease after B:9-23/IFA treatment would still be seen. In order to address the contribution of IL-4 production to tolerance induction after B:9-23/IFA treatment, NOD/ $\mathrm{Il4}^{-/-}$mice were used. In these mice, progression to diabetes was still prevented after B:9-23/IFA treatment, suggesting that IL-4 production is not necessary for achieving tolerance. The contribution of TGF-beta-1 was not directly addressed in the present study, but its importance in mediating antigen-specific tolerance has been shown previously [39-41].

In order to further elucidate the immunomodulatory potential of the B:9-23-induced Tregs, cells from protected donors were isolated, expanded in vitro, separated into $\mathrm{CD} 4^{+} \mathrm{CD} 25^{+}$and $\mathrm{CD} 4^{+} \mathrm{CD} 25^{-}$fractions and adoptively transferred into prediabetic hosts. The in vitro culture step seemed to be important for enhancing $\mathrm{CD} 4^{+} \mathrm{CD} 25^{+}$regulatory properties, perhaps due to an increase in B:9-23-specific Treg qualities. Inclusion of cells from age-matched control mice was not possible since more than $90 \%$ of them developed diabetes, while cells from the remaining ones failed to grow under the same culture conditions. Additional analysis revealed a link between IFN $\gamma /$ IL-10 production and Tregs, in that the $\mathrm{CD} 4^{+} \mathrm{CD} 25^{+}$B:9-23-expanded cells were high producers of both cytokines, but not co-producers. In follow-up studies, IFN $\gamma$ production was associated with protection from diabetes in $\mathrm{CD} 4^{+} \mathrm{CD} 25^{+}$cell transfers. Recent evidence suggests that IFN $\gamma$ can be important for protection from diabetes and other autoimmune diseases [42-46]. More recently in diabetes, IFN $\gamma$ production was shown to suppress the pathogenic activity of Th17 cells [47]. Upon B:9-23/IFA immunisation, we observed neither strong induction nor significant reduction of IL-17 production. While IL-17 levels remained constant, IFN $\gamma$ production and the IFN $\gamma:$ IL-17 ratio were increased. To further understand the contribution of IFN $\gamma$ in B:9-23/IFA-induced tolerance, adoptive transfers with cells enriched in IFN $\gamma$ production were done. A delay in disease progression was seen, suggesting that this population has at least transient regulatory properties and that other Tregs or other IL-10-producing cells are necessary for establishing prolonged tolerance.

In conclusion, IFN $\gamma$ and IL-10 are important mediators of B:9-23/IFA-induced tolerance. Additional analyses will be required to understand the precise role of inflammatory cytokines such as IFN $\gamma$ in Treg-mediated suppression of autoimmunity. To date, treatment with anti-CD3 antibody alone or in conjunction with nasal (pro)insulin therapy has been shown to reverse diabetes and to suppress disease recurrence [48]. The capacity of InsB:9-23/IFA immunisation to reverse diabetes as a monotherapy or in conjunction with other drugs such as Abatacept (CTLA4-Ig) has not yet been tested. It is also possible that as antigens spread with disease progression, a combination of more than one autoantigen such as GAD65, GAD2 and IA-2 may be necessary to induce tolerance $[13,49]$. Ideally, the use of more aggressive immunomodulatory regimens should be limited in time and dose, thus avoiding some of their negative side effects. This can be achieved by combining antigen-specific interventions with systemically acting agents.

Acknowledgements We gratefully acknowledge support from Brehm coalition, NIH and Juvenile Diabetes Research Foundation funds. We would like to thank K. Coppieters, N. Amirian and M. McClure for technical help, and P. Colby for administrative assistance. G. Fousteri is an American Heart Association scholar award recipient.

Duality of interest The authors declare that there is no duality of interest associated with this manuscript.

Open Access This article is distributed under the terms of the Creative Commons Attribution Noncommercial License which permits any noncommercial use, distribution, and reproduction in any medium, provided the original author(s) and source are credited. 


\section{References}

1. Di Lorenzo TP, Peakman M, Roep BO (2007) Translational minireview series on type 1 diabetes: systematic analysis of $\mathrm{T}$ cell epitopes in autoimmune diabetes. Clin Exp Immunol 148:1-16

2. Alleva DG, Crowe PD, Jin L et al (2001) A disease-associated cellular immune response in type 1 diabetics to an immunodominant epitope of insulin. J Clin Invest 107:173-180

3. Peakman M, Stevens EJ, Lohmann T et al (1999) Naturally processed and presented epitopes of the islet cell autoantigen IA-2 eluted from HLA-DR4. J Clin Invest 104:1449-1457

4. Kent SC, Chen Y, Bregoli L et al (2005) Expanded T cells from pancreatic lymph nodes of type 1 diabetic subjects recognize an insulin epitope. Nature 435:224-228

5. Nakayama M, Abiru N, Moriyama H et al (2005) Prime role for an insulin epitope in the development of type 1 diabetes in NOD mice. Nature 435:220-223

6. Nakayama M, Beilke JN, Jasinski JM et al (2007) Priming and effector dependence on insulin B:9-23 peptide in NOD islet autoimmunity. J Clin Invest 117:1835-1843

7. Nakayama M, Babaya N, Miao D et al (2006) Long-term prevention of diabetes and marked suppression of insulin autoantibodies and insulitis in mice lacking native insulin B9-23 sequence. Ann NY Acad Sci 1079:122-129

8. Shoda LK, Young DL, Ramanujan S et al (2005) A comprehensive review of interventions in the NOD mouse and implications for translation. Immunity 23:115-126

9. Filippi C, Bresson D, von Herrath M (2005) Antigen-specific induction of regulatory $\mathrm{T}$ cells for type 1 diabetes therapy. Int Rev Immunol 24:341-360

10. Azam A, Eisenbarth GS (2004) Immunopathogenesis and immunotherapeutic approaches to type 1A diabetes. Expert Opin Biol Ther 4:1569-1575

11. von Herrath M, Rottembourg D, Bresson D (2006) Progress in the development of immune-based therapies for type 1 diabetes mellitus. BioDrugs 20:341-350

12. McDevitt H (2004) Specific antigen vaccination to treat autoimmune disease. Proc Natl Acad Sci USA 101(Suppl 2):1462714630

13. Fousteri G, Bresson D, von Herrath M (2007) Rational development of antigen-specific therapies for type 1 diabetes. Adv Exp Med Biol 601:313-319

14. Daniel D, Wegmann DR (1996) Protection of nonobese diabetic mice from diabetes by intranasal or subcutaneous administration of insulin peptide B-(9-23). Proc Natl Acad Sci USA 93:956-960

15. Hutchings P, Cooke A (1998) Protection from insulin dependent diabetes mellitus afforded by insulin antigens in incomplete Freund's adjuvant depends on route of administration. J Autoimmun 11:127-130

16. Liu E, Abiru N, Moriyama H, Miao D, Eisenbarth GS (2002) Induction of insulin autoantibodies and protection from diabetes with subcutaneous insulin B:9-23 peptide without adjuvant. Ann NY Acad Sci 958:224-227

17. Mukherjee R, Chaturvedi P, Qin HY, Singh B (2003) CD4 $4^{+} \mathrm{CD} 25^{+}$ regulatory $\mathrm{T}$ cells generated in response to insulin $\mathrm{B}: 9-23$ peptide prevent adoptive transfer of diabetes by diabetogenic T cells. J Autoimmun 21:221-237

18. Staeva-Vieira T, Peakman M, von Herrath M (2007) Translational mini-review series on type 1 diabetes: immune-based therapeutic approaches for type 1 diabetes. Clin Exp Immunol 148:17-31

19. Devendra D, Paronen J, Liu E et al (2004) Comparative study of oral vs subcutaneous B:9-23 insulin peptide in Balb/c mice as an experimental model for autoimmune diabetes. Ann NY Acad Sci 1029:331-333
20. Devendra D, Paronen J, Moriyama H, Miao D, Eisenbarth GS, Liu E (2004) Differential immune response to B:9-23 insulin 1 and insulin 2 peptides in animal models of type 1 diabetes. $\mathrm{J}$ Autoimmun 23:17-26

21. Fukushima K, Abiru N, Nagayama Y et al (2008) Combined insulin B:9-23 self-peptide and polyinosinic-polycytidylic acid accelerate insulitis but inhibit development of diabetes by increasing the proportion of $\mathrm{CD} 4^{+} \mathrm{Foxp}^{+}$regulatory $\mathrm{T}$ cells in the islets in non-obese diabetic mice. Biochem Biophys Res Commun 367:719-724

22. Kobayashi M, Abiru N, Arakawa T et al (2007) Altered B:9-23 insulin, when administered intranasally with cholera toxin adjuvant, suppresses the expression of insulin autoantibodies and prevents diabetes. J Immunol 179:2082-2088

23. Trudeau JD, Kelly-Smith C, Verchere CB et al (2003) Prediction of spontaneous autoimmune diabetes in NOD mice by quantification of autoreactive $\mathrm{T}$ cells in peripheral blood. J Clin Invest 111:217-223

24. Kaufman DL, Clare-Salzler M, Tian J et al (1993) Spontaneous loss of T-cell tolerance to glutamic acid decarboxylase in murine insulin-dependent diabetes. Nature 366:69-72

25. Cobbold S, Waldmann H (1998) Infectious tolerance. Curr Opin Immunol 10:518-524

26. Harrison LC, Hafler DA (2000) Antigen-specific therapy for autoimmune disease. Curr Opin Immunol 12:704-711

27. Homann D, Holz A, Bot A et al (1999) Autoreactive CD4 ${ }^{+} \mathrm{T}$ cells protect from autoimmune diabetes via bystander suppression using the IL-4/Stat6 pathway. Immunity 11:463-472

28. Larche M, Wraith DC (2005) Peptide-based therapeutic vaccines for allergic and autoimmune diseases. Nat Med 11:S69-76

29. Arif S, Tree TI, Astill TP et al (2004) Autoreactive T cell responses show proinflammatory polarization in diabetes but a regulatory phenotype in health. J Clin Invest 113:451-463

30. Tian J, Atkinson MA, Clare-Salzler M et al (1996) Nasal administration of glutamate decarboxylase (GAD65) peptides induces Th2 responses and prevents murine insulin-dependent diabetes. J Exp Med 183:1561-1567

31. Orban T, Farkas K, Jalahej H et al (2009) Autoantigen-specific regulatory $\mathrm{T}$ cells induced in patients with type 1 diabetes mellitus by insulin B-chain immunotherapy. J Autoimmun. doi:10.1016/j. jaut.2009.10.005

32. Every AL, Kramer DR, Mannering SI, Lew AM, Harrison LC (2006) Intranasal vaccination with proinsulin DNA induces regulatory $\mathrm{CD}^{+} \mathrm{T}$ cells that prevent experimental autoimmune diabetes. J Immunol 176:4608-4615

33. Sakaguchi S (2005) Naturally arising Foxp3-expressing $\mathrm{CD} 25^{+} \mathrm{CD}^{+}$regulatory $\mathrm{T}$ cells in immunological tolerance to self and non-self. Nat Immunol 6:345-352

34. Zheng Y, Rudensky AY (2007) Foxp3 in control of the regulatory T cell lineage. Nat Immunol 8:457-462

35. Li MO, Flavell RA (2008) Contextual regulation of inflammation: a duet by transforming growth factor-beta and interleukin- 10 . Immunity 28:468-476

36. Li MO, Flavell RA (2008) TGF-beta: a master of all T cell trades. Cell 134:392-404

37. von Boehmer H (2005) Mechanisms of suppression by suppressor T cells. Nat Immunol 6:338-344

38. Wing K, Onishi Y, Prieto-Martin P et al (2008) CTLA-4 control over Foxp3 ${ }^{+}$regulatory $\mathrm{T}$ cell function. Science 322:271-275

39. Fousteri G, von Herrath M, Bresson D (2007) Mucosal exposure to antigen: cause or cure of type 1 diabetes? Curr Diab Rep 7:9198

40. Ostroukhova M, Seguin-Devaux C, Oriss TB et al (2004) Tolerance induced by inhaled antigen involves CD4(+) T cells expressing membrane-bound TGF-beta and FOXP3. J Clin Invest $114: 28-38$ 
41. Weiner HL (2001) Oral tolerance: immune mechanisms and the generation of Th3-type TGF-beta-secreting regulatory cells. Microbes Infect 3:947-954

42. Billiau A, Heremans H, Vandekerckhove F et al (1988) Enhancement of experimental allergic encephalomyelitis in mice by antibodies against IFN-gamma. J Immunol 140:1506-1510

43. Chen C, Liu CP (2009) Regulatory function of a novel population of mouse autoantigen-specific Foxp3 regulatory T cells depends on IFN-gamma, NO, and contact with target cells. PLoS ONE 4:e7863

44. Flaishon L, Topilski I, Shoseyov D et al (2002) Cutting edge: antiinflammatory properties of low levels of IFN-gamma. J Immunol 168:3707-3711

45. Kelchtermans H, Struyf S, De Klerck B et al (2007) Protective role of IFN-gamma in collagen-induced arthritis conferred by inhibition of mycobacteria-induced granulocyte chemotactic protein-2 production. J Leukoc Biol 81:1044-1053
46. Tarrant TK, Silver PB, Wahlsten JL et al (1999) Interleukin 12 protects from a $\mathrm{T}$ helper type 1-mediated autoimmune disease, experimental autoimmune uveitis, through a mechanism involving interferon gamma, nitric oxide, and apoptosis. J Exp Med 189:219-230

47. Jain R, Tartar DM, Gregg RK et al (2008) Innocuous IFNgamma induced by adjuvant-free antigen restores normoglycemia in NOD mice through inhibition of IL-17 production. J Exp Med 205:207-218

48. Bresson D, Togher L, Rodrigo E et al (2006) Anti-CD3 and nasal proinsulin combination therapy enhances remission from recentonset autoimmune diabetes by inducing Tregs. J Clin Invest 116:1371-1381

49. Bresson D, von Herrath M (2007) Moving towards efficient therapies in type 1 diabetes: to combine or not to combine? Autoimmun Rev 6:315-322 